\title{
Defect Chemistry of the Mixed Conducting Cage Compound $\mathrm{Ca}_{12} \mathrm{Al}_{14} \mathrm{O}_{33}{ }^{\star}$
}

\author{
J. Janek ${ }^{\dagger}$ and D.-K. Lee \\ Institute of Physical Chemistry, Justus-Liebig-University, Heinrich-Buff-Ring 58, D-35392 Giessen, Germany
}

(Received January 20, 2010; Accepted February 12, 2010)

\begin{abstract}
The electrical transport properties of mayenite $\left(\mathrm{Ca}_{12} \mathrm{Al}_{14} \mathrm{O}_{33}\right.$ or $12 \mathrm{CaO} \cdot 7 \mathrm{Al}_{2} \mathrm{O}_{3}$; mostly abbreviated as $\left.\mathrm{C}_{12} \mathrm{~A}_{7}\right)$ can be controlled in a wide range by varying the oxygen deficiency: At high temperatures mayenite becomes either an oxygen solid electrolyte, a mixed ionic/electronic conductor or an inorganic electride with metal-like properties upon chemical reduction (removing oxygen). The underlying defect chemistry can be understood on the basis of a relatively simple model - despite the complex cage structure: A point defect model based on the assumption that the framework $\left[\mathrm{Ca}_{12} \mathrm{Al}_{14} \mathrm{O}_{32}\right]^{2+}$ acts as a pseudo-donor describes well the high temperature transport properties. It accounts for the observed conductivity plateau at higher oxygen activities and also describes the experimentally observed oxygen activity dependence of the electronic conductivity with $-1 / 4$ slope at temperatures between 800 and $1000^{\circ} \mathrm{C}$. Doping effects in mayenite are still not well explored, and we review briefly the existing data on doping by different elements. Hydration of mayenite plays a crucial role, as Mayenite is hygroscopic, which may be a major obstacle for technical applications.
\end{abstract}

Key words: Mayenite, $\mathrm{Ca}_{12} \mathrm{Al}_{14} \mathrm{O}_{33}$, Electronic conductivity, Ionic conductivity, Defect structure, $C_{12} A_{7}$

\section{Introduction}

M ayenite $\left(\mathrm{Ca}_{12} \mathrm{Al}_{14} \mathrm{O}_{33}\right.$, often denoted as $\mathrm{C}_{12} \mathrm{~A}_{7}$ to which the quasi-binary compound $12 \mathrm{CaO} \cdot 7 \mathrm{Al}_{2} \mathrm{O}_{3}$ is abbreviated) has recently become an extensively studied mixed conducting ceramic. ${ }^{1)}$ Its high ionic conductivity was first reported in 1988 by Lacerda et al., ${ }^{2)}$ being roughly an order of magnitude lower than that of yttria-stabilized zirconia (being the most extensively employed oxygen electrolyte). Before this experimental report most studies on $\mathrm{C}_{12} \mathrm{~A}_{7}$ had before dealt with its crystallographic cage structure. ${ }^{3,4}$ The crystal lattice belongs to the cubic system of space group $I 4 \overline{3} d$ with a lattice parameter of $1.199 .{ }^{4)}$ Shortly after Lacerda's first report the same group also reported that polycrystalline C12A7 is hygroscopic and that the ionic conductivity of C12A7 degrades by hydration. ${ }^{5)}$ Lacerda et al. also were the first to show that $\mathrm{C} 12 \mathrm{~A} 7$ can be reduced chemically and becomes a mixed conductor thereupon. ${ }^{6}$ Ten years later Sushko et al. excavated C12A7 and showed that it becomes an electride upon reduction by $\mathrm{Ca}$ metal or in hydrogen-bearing gas followed by UV-light irradiation. ${ }^{7)}$ Numerous experimental and theoretical studies have been made thereafter to reveal the transition of $\mathrm{C}_{12} \mathrm{~A}_{7}$ from an

\footnotetext{
${ }^{\star}$ Based on a Invited talk by Professor Janek, presented at 6th Petit Workshop on Defect Chemical Nature of Energy Materials (Damyang, SEP. 6-9, 2009).

Corresponding author: J. Janek

E-mail : Juergen.Janek@phys.Chemie.uni-giessen.de

Tel : +49-641-99-34515 Fax : +49-641-99-34509

${ }^{ \pm}$Current Address: Solar Cell Center, Korea Institute of Science and Technology (KIST), Seoul, 136-791, Korea; E-mail: dklee@kist.re.kr
}

ionic conductor to an electride. ${ }^{8-16)}$ Besides, the possibility of incorporation of various anions e.g., halides $\left(\mathrm{F}^{-}, \mathrm{Cl}^{-}\right),{ }^{3)}$ oxygen radicals $\left(\mathrm{O}_{2}^{-}, \mathrm{O}^{-}\right),{ }^{17,18)}$ and hydroxide $\left(\mathrm{OH}^{-}\right)^{19)}$ into the C12A7 lattice forms another interesting feature of mayenite which has been studied also in some detail.

These rather specific transport properties can be attributed to the cage structure of crystalline C12A7: The framework of $\mathrm{Ca}_{12} \mathrm{Al}_{14} \mathrm{O}_{33}$ is made up of a 3-dimensional network of corner-sharing $\mathrm{AlO}_{4}$ tetrahedra together with seven-coordinated $\mathrm{Ca}$ ions, and six crystallographic cages of a subnanometer size $(\sim 0.4 \mathrm{~nm}$ in diameter) therein (Fig. 1). An additional oxygen ion, which is called 'free oxygen' or 'extraframework oxygen' (as it does not reside in cage framework), occupies one of the cages to maintain charge neutrality of the crystal. The free oxygen is loosely bound to the cage with six $\mathrm{Ca}^{2+}$, $)$ and the high ionic conductivity and the possibility of replacement of oxygen by electrons and/or another anions are easily understood.

The detailed defect structure of this interesting oxide system, however, has not been systematically explored yet, in particular with respect to doping effects. Hosono and his coworkers determined the electronic charge carrier concentration for different degrees of reduction, but a systematic study of the nonstoichiometry of $\mathrm{C} 12 \mathrm{~A} 7$ has yet not been published. The partial ionic and electronic conductivites at elevated temperature as a function of oxygen activity (from pure oxygen to low oxygen activities) have been studied by Lee and Janek. ${ }^{20)}$ And recently, Kim et al. reported on the thermoelectric properties of Mayenite for different electronic charge carrier concentrations. ${ }^{21)}$ Interestingly, the oxygen hyperstoichiometry, as caused by $\mathrm{O}_{2}-$ or $\mathrm{O}_{2}{ }^{2-}$ species has yet not been explored quantitatively. In the following, 


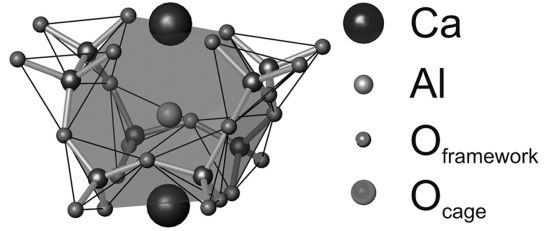

(a)
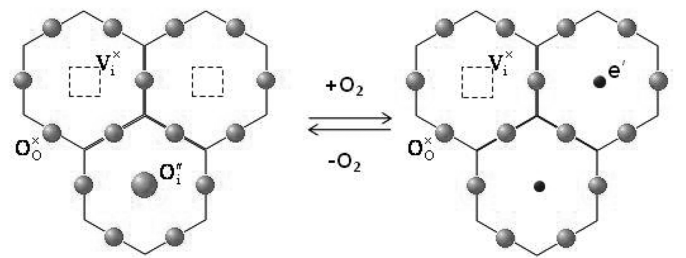

(b)
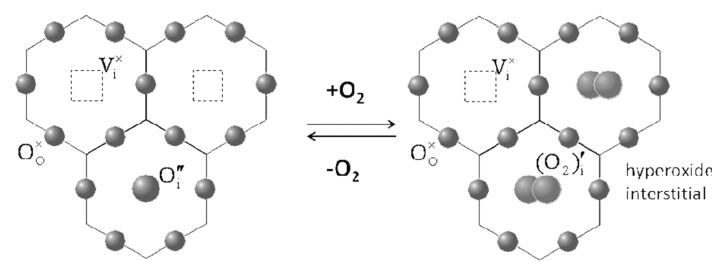

(c)

Fig. 1. (a) Illustration of $\mathrm{Ca}_{12} \mathrm{Al}_{14} \mathrm{O}_{33-\delta}$ crystal lattice (reproduced by permission of the PCCP owner societies). (b) Illustration of the reduction process leading to the formation of cage electrons and (c) illustration of the incorporation of excess oxygen as hyperoxide species.

we summarize the existing understanding of $\mathrm{C} 12 \mathrm{~A} 7$ from the viewpoint of defect chemistry.

\section{Defect chemistry of $\mathrm{Ca}_{12} \mathrm{Al}_{14} \mathrm{O}_{33}$}

West et al. demonstrated by concentration cell experiments that the total conductivity measured in laboratory air is attributed to doubly charged oxide ions. ${ }^{222)}$ The question arises whether this fairly high ionic conductivity originates from intrinsic defects, or has an extrinsic origin as is the case with other electrolytes, e.g. YSZ ${ }^{23)}$ or GDC. ${ }^{24)}$

Mayenite, $\mathrm{C}_{12} \mathrm{Al}_{14} \mathrm{O}_{33}$ has two types of oxide anions, one (framework oxygen) belonging to the aluminate framework formed by eightfold corner-sharing tetrahedra, $\left[\mathrm{Al}_{14} \mathrm{O}_{32}\right]^{22-}$ and the other (cage oxygen; free oxygen) randomly distributed within the cages of the framework. The stoichiometric mayenite crystal consists of the positively charged framework $\left[\mathrm{Ca}_{12} \mathrm{Al}_{14} \mathrm{O}_{32}\right]^{2+}$ per molecular formula unit, forming six crystallographic cages. The additional oxygen ion occupies one of six chemically equivalent cages randomly. Thus, mayenite inherently has 5/6 of empty out-of-framework oxygen sites (cage sites) as structural vacancies. In stoichiometric $\mathrm{C}_{12} \mathrm{~A}_{7}$, i.e., $\left[\mathrm{Ca}_{12} \mathrm{Al}_{14} \mathrm{O}_{32}\right]^{2+}:\left(\mathrm{O}^{2-}\right)$ or $\mathrm{C}_{12} \mathrm{~A}_{7}: \mathrm{O}^{2-}$, however, the remaining five cages are no more equivalent to the 'free oxygen' sites because the occupation of cages by oxygen ions results in the distortion of the lattice. From the defect-chemical viewpoint it is the main question of how the cage oxygen

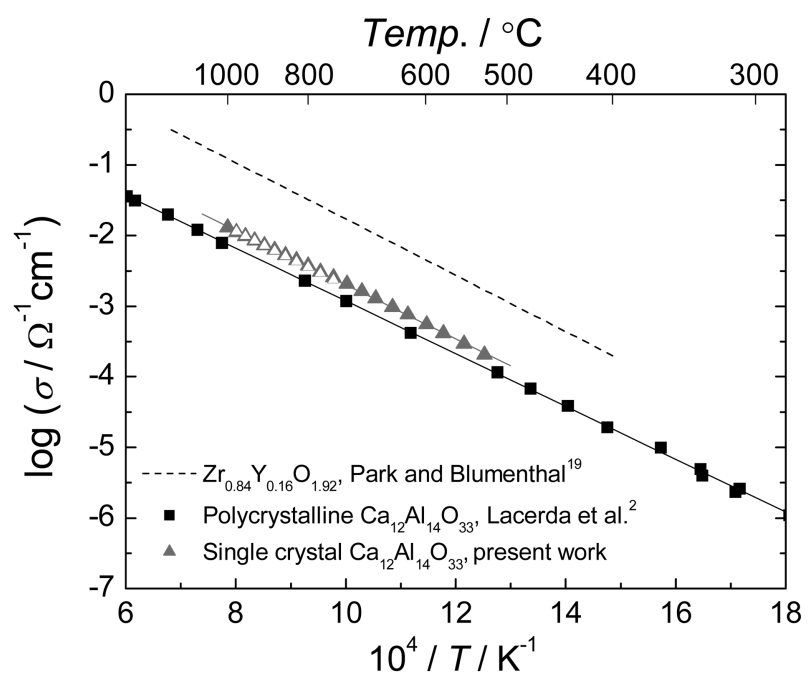

(a)

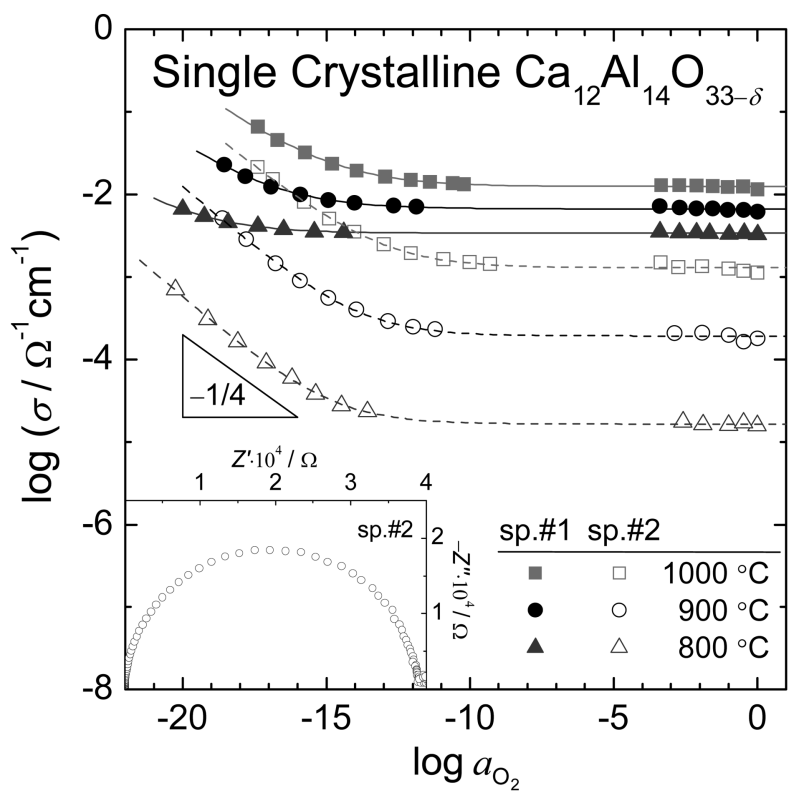

(b)

Fig. 2. Total electrical conductivity $\sigma$ of single crystalline $\mathrm{Ca}_{12} \mathrm{Al}_{14} \mathrm{O}_{33-\delta}:$ (a) $\log \sigma$ in dry air vs. reciprocal temperature, (b) log $\sigma v s$. oxygen activity at different temperatures for specimen \#1 (solid symbol) measured in dry condition and for specimen \#2 (open symbol) in laboratory humidity after six months' annealing at $900^{\circ} \mathrm{C}$. Inset in (b) shows the typical impedance response of specimen \#2. The solid and dashed curves in (b) are the best-fitted to Eq. (12).

and empty cages have to be formally described in order to develop a correct defect model of mayenite.

Hosono and his group ${ }^{25)}$ described the reduction equilibrium of $\mathrm{C}_{12} \mathrm{~A}_{7}$ with $\mathrm{CO}_{2} / \mathrm{CO}$ gas mixture using building units such as $\mathrm{O}^{2-}$ (cage) and $\mathrm{e}^{-}$(cage). Their straightforward treatment describes the reduction regime relatively well, but it is too simple as a general model: The charge neutrality condition, $2 \cdot x\left(\mathrm{O}^{2-}\right)+x\left(\mathrm{e}^{-}\right)=2$ with $x$ being mole fraction of each species, which they proposed, does not describe i) p-type 


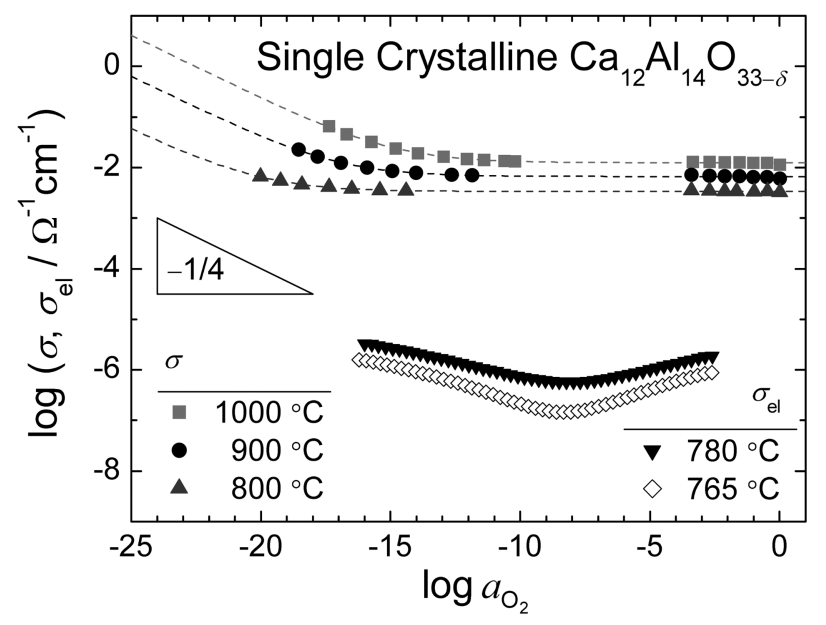

Fig. 3. Electronic partial conductivities $\sigma_{\text {el }} v s$. oxygen activity at different temperatures of single crystalline mayenite. Total conductivities in Fig. 2(b) are also represented for comparison purpose.

electronic conductivity (Fig. 3) ii) hyper-stoichiometry, ${ }^{26-28)}$ i.e., $\delta<0$ in $\mathrm{Ca}_{12} \mathrm{Al}_{14} \mathrm{O}_{33-\delta}$ (any excess oxygen would result in a negative concentration of electrons according to their charge neutrality equation); iii) the constant concentration of ionic carriers with the concomitant increase of the electron concentration as oxygen activity decreases over a wide range.

The electronic structure of $\mathrm{C}_{12} \mathrm{~A}_{7}$, in particular, the spatial distribution of electrons introduced in place of oxygen ions upon reduction has been a subject of intense discussion. Sushko et al. ${ }^{7)}$ proposed that the extra electron in $\mathrm{C}_{12} \mathrm{~A}_{7}$ is localized in a cage acting as a polaron or a quasi-anion, thus supporting the electride model. Medvedeva et al. ${ }^{13,14)}$ revealed by first-principle calculation of the electronic structure of $\left[\mathrm{Ca}_{12} \mathrm{Al}_{14} \mathrm{O}_{32}\right]^{2+}:\left(2 \mathrm{e}^{-}\right)$or $\mathrm{C}_{12} \mathrm{~A}_{7}: 2 \mathrm{e}^{-}$that the conduction electrons are highly delocalized in the cages as well as in the regions occupied with cations. Pseudo-potential plane calculations by $\mathrm{Li}$ et al., ${ }^{15)}$ on the other hand, showed that the electron density is equally distributed, but being localized in the 6 cages with nonstoichiometry. In a more recent theoretical study, Sushko et al. ${ }^{11)}$ suggested that the electronic structure of $\mathrm{C}_{12} \mathrm{~A}_{7}:\left(\mathrm{O}^{2-}\right)_{1-x}\left(\mathrm{e}^{-}\right)_{2 x}(0 \leq x \leq 1)$ undergoes a gradual transition from localized state to delocalized one over the cages with increasing electron concentration $x$, which was also experimentally verified by Matsuishi et al. ${ }^{12)}$ who demonstrated a change of conduction mechanism of electron from hopping to metallic one with increasing $x$. The most recent structural study using synchrotron X-ray diffraction by Palacios et al. ${ }^{16)}$ showed electron density localized into the center of the cages in $\mathrm{C}_{12} \mathrm{~A}_{7}:\left(\mathrm{O}^{2-}\right)_{0.55}\left(\mathrm{e}^{-}\right)_{0.9}$.

\subsection{Partial electrical conductivities}

One may regard the framework of $\mathrm{C}_{12} \mathrm{~A}_{7}$, i.e., $\left[\mathrm{Ca}_{12} \mathrm{Al}_{14} \mathrm{O}_{32}\right]^{2+}$, acting as a doubly charged pseudo-donor, $\mathrm{D}_{\mathrm{FW}}^{\bullet \bullet}$, of which concentration is fixed by the molecular density $\left(\beta \equiv N_{\mathrm{A}} / V_{\mathrm{m}}=1.16 \times 10^{21} \mathrm{~cm}^{-3}\right.$ where $N_{\mathrm{A}}, V_{\mathrm{m}}$ are Avogadro's number, molar volume of $\mathrm{C}_{12} \mathrm{~A}_{7}$ ), and six cages as neutral interstitial sites, $\mathrm{I}_{\mathrm{i}}^{\times}$(regular structure element). The extraframework oxygen (cage oxygen; free oxygen) may then be treated as doubly ionized interstitial oxygen, $\mathrm{O}_{i}^{\prime \prime}$ (irregular structure element) in terms of Kroeger-Vink notation. Since there are five additional cages, $\mathrm{I}_{\mathrm{i}}^{\times}$, for stoichiometric mayenite, $\mathrm{C}_{12} \mathrm{~A}_{7}:\left(\mathrm{O}^{2-}\right)$, we can assume that a thermal equilibrium (anti-Frenkel type disorder) may give rise to a fraction of framework oxygen, $\mathrm{O}_{\mathrm{O}}^{\times}$, residing at the interstitial sites leaving the corresponding number of lattice oxygen vacancies $\mathrm{V}_{\mathrm{O}}^{\bullet \bullet}$ in the framework. Equilibrium for electron $\left(\mathrm{e}^{\prime}\right)$ hole $\left(h^{\circ}\right)$ pair formation is also assumed. Accepting the theoretical results for a gradual change of the electron localization, ${ }^{11,12)}$ it is reasonable to represent electrons as $\mathrm{e}_{\mathrm{i}}^{\prime}$ as long as the degree of reduction of is much less than the metal/ metal oxide equilibrium in which the transition is reported to be complete. ${ }^{12)}$ Taking into account all relevant structure elements, the charge neutrality condition is then given as

$$
\begin{aligned}
& 2\left[\mathrm{D}_{\mathrm{FW}}^{\bullet \bullet}\right]+2\left[\mathrm{~V}_{\mathrm{O}}^{\bullet \bullet}\right]+p=2\left[\mathrm{O}_{\mathrm{i}}^{\prime \prime}\right]+n \text { or } \\
& 2 \beta+2\left[\mathrm{~V}_{\mathrm{O}}^{\bullet \bullet}\right]+p=2\left[\mathrm{O}_{\mathrm{i}}^{\prime \prime}\right]+n
\end{aligned}
$$

along with external (reduction) and internal equilibria as

$$
\begin{aligned}
& \mathrm{O}_{\mathrm{i}}^{\prime \prime}+\mathrm{I}_{\mathrm{i}}^{\times}=2 \mathrm{e}_{\mathrm{i}}^{\prime}+\frac{1}{2} \mathrm{O}_{2}(\mathrm{~g}) ; \quad K_{R}=\frac{n^{2}}{\left[\mathrm{O}_{i}^{\prime \prime}\right]} \cdot a_{O_{2}}^{1 / 2} \\
& \mathrm{O}_{\mathrm{O}}^{\times}+\mathrm{I}_{\mathrm{i}}^{\times}=\mathrm{V}_{\mathrm{O}}^{\bullet \bullet}+\mathrm{O}_{\mathrm{i}}^{\prime \prime}, \quad K_{\mathrm{AF}}=\left[\mathrm{V}_{\mathrm{O}}^{\bullet \bullet}\right] \cdot\left[\mathrm{O}_{\mathrm{i}}^{\prime \prime}\right] \\
& \text { null }=\mathrm{e}^{\prime}+\mathrm{h}^{\bullet} ; \quad K_{\mathrm{i}}=n \cdot p
\end{aligned}
$$

where [D] stands for the concentration of defect species D (= $\left.\mathrm{D}_{\mathrm{FW}}^{\bullet \bullet}, \mathrm{O}_{\mathrm{i}}^{\prime \prime}, \mathrm{V}_{\mathrm{O}}^{\bullet \bullet}\right)$, and $n, p$ for the concentration of electrons and holes, in $\mathrm{cm}^{-3}$, respectively. $K_{\mathrm{j}}$ denotes the equilibrium constant for the associated reaction $j(j=\mathrm{R}, \mathrm{AF}, \mathrm{i})$. The nonstoichiometry, $\delta$, the deviation from the (electronic) stoichiometic composition ( $\delta \equiv 0)$, is defined as

$\beta \delta=\left[\mathrm{V}_{\mathrm{O}}^{\bullet \bullet}\right]-\left(\left[\mathrm{O}_{\mathrm{i}}^{\prime \prime}\right]-\left[\mathrm{D}_{\mathrm{FW}}^{\bullet \bullet \bullet}\right]\right)=\frac{1}{2}(n-p)$

The electronic defect concentration can be characterized with the oxygen nonstoichiometry $\delta$ as $\mathrm{Ca}_{12} \mathrm{Al}_{14} \mathrm{O}_{33-\delta}$ Four majority disorder types can be distinguished from Eq. (1) to get the solution to Eqs. (1) (4) as shown in Fig. 4: As the oxygen activity increases, the disorder type shifts from $\left(\mathrm{V}_{\mathrm{O}}^{\bullet \bullet}, \mathrm{e}^{\prime}\right)$ to $\left(\mathrm{e}^{\prime}, \mathrm{D}_{\mathrm{FW}}^{\bullet \bullet}\right)$ to $\left(\mathrm{D}_{\mathrm{FW}}^{\bullet \bullet}, \mathrm{O}_{\mathrm{i}}^{\prime \prime}\right)$ to $\left(\mathrm{O}_{\mathrm{i}}^{\prime \prime}, \mathrm{h}^{\bullet}\right)$, in turn.

In the near stoichiometric regime $(n \approx p)$, the positively charged pseudo-donor, $\mathrm{D}_{\mathrm{FW}}^{\bullet \bullet}$, is compensated by interstitial oxygen, $\mathrm{O}_{\mathrm{i}}^{\prime \prime}$, that is, Eq. (1) can be simplified as

$$
\left[\mathrm{D}_{\mathrm{FW}}^{\bullet \bullet}\right] \approx\left[\mathrm{O}_{\mathrm{i}}^{\prime \prime}\right]
$$

Combining Eqs. (2), (4) and (6), the concentration of electronic charge carriers, $n$ and $p$, are calculated respectively as

$$
n \approx \sqrt{K_{i}}\left(\frac{a_{O_{2}}}{a_{O_{2}}^{\circ}}\right)^{-1 / 4}, p \approx \sqrt{K_{i}}\left(\frac{a_{O_{2}}}{a_{O_{2}}^{\circ}}\right)^{+1 / 4}
$$

Here $a_{O_{2}}^{\circ}$ is the oxygen activity corresponding to the stoichiometric composition ( $\delta \equiv 0)$ where $n=p=K_{\mathrm{i}}^{1 / 2}$. Similarly, 


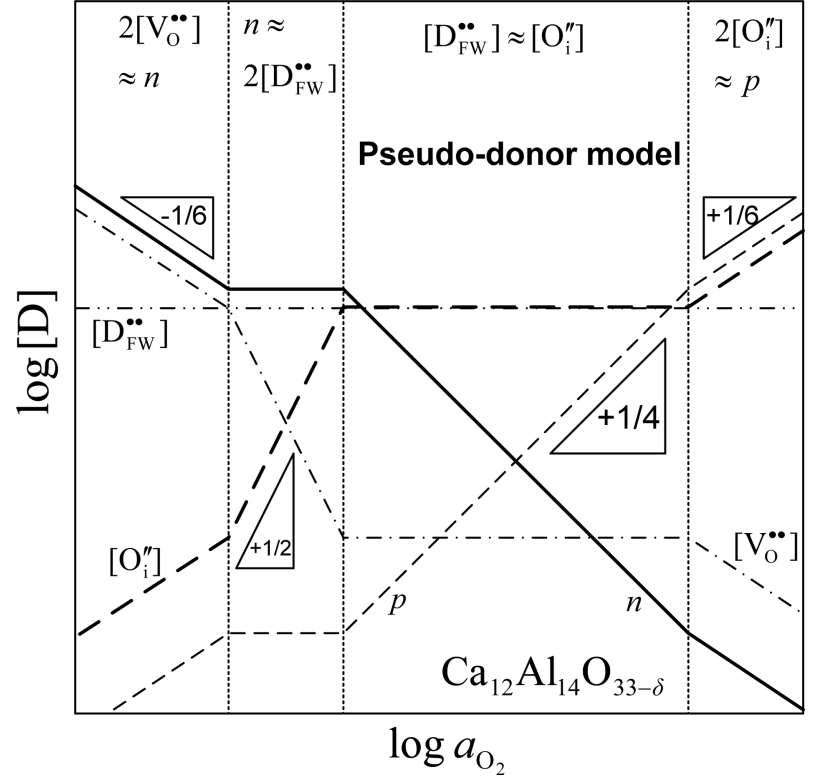

Fig. 4. Kroeger-Vink diagram of $\mathrm{Ca}_{12} \mathrm{Al}_{14} \mathrm{O}_{33-\delta}$ The vertical dashed lines are the boarders between different majority disorder regimes and the numbers inside triangles denote the oxygen exponents $m$ such that $[\mathrm{D}] \propto a_{\mathrm{O}_{2}}^{m}$.

by solving Eqs. (2) (4) with simplified charge neutrality constraints, $2\left[\mathrm{~V}_{\mathrm{O}}^{\bullet \bullet}\right] \approx n, n \approx 2\left[\mathrm{D}_{\mathrm{FW}}^{\bullet \bullet}\right],\left[\mathrm{D}_{\mathrm{FW}}^{\bullet \bullet}\right] \approx\left[\mathrm{O}_{\mathrm{i}}^{\prime \prime}\right], 2\left[\mathrm{O}_{\mathrm{i}}^{\prime \prime}\right] \approx p$, in tandem, one can represent the defect diagram of mayenite as illustrated in Fig. 4.

The migration of oxygen may take place with the aid of interstitials $\mathrm{O}_{\mathrm{i}}^{\prime \prime}$ and/or vacancies $\mathrm{V}_{\mathrm{O}}^{\text {:• }}$ : i) an extra-framework oxygen $\mathrm{O}_{i}^{\prime \prime}$ displaces a neighboring framework oxygen $\mathrm{O}_{\mathrm{O}}^{\times}$ into an another empty cage site $\mathrm{I}_{\mathrm{i}}^{\times}$and itself taking the place of the displaced lattice ion (interstitialcy mechanism); ii) an interstitial oxygen $\mathrm{O}_{\mathrm{i}}^{\prime \prime}$ moves between adjacent interstitial sites through the opening on the cage wall (interstitial mechanism); iii) a lattice oxygen $\mathrm{O}_{\mathrm{O}}^{\times}$exchanges its position with a vacancy $\mathrm{V}_{\mathrm{O}}^{\bullet \bullet}$ (vacancy mechanism). Theoretical calculations shows that the interstitialcy mechanism is energetically most favored in mayenite crystal, ${ }^{29)}$ which is in line with a neutron diffraction study. ${ }^{26)}$ An ${ }^{18} \mathrm{O}$ exchange experiment followed by Raman spectroscopy ${ }^{30}$ indicates that the local fraction of ${ }^{18} \mathrm{O}$ is equal between the framework and extra-framework sites, thus implying that the exchange of the oxygen ion in the framework, $\mathrm{O}_{\mathrm{O}}^{\times}$, can be easily achieved with the extra-framework oxygen, $\mathrm{O}_{i}^{\prime \prime}$, consequently supporting the interstitialcy mechanism.

When the oxygen transport takes place via interstitialcy mechanism, the oxygen ion conductivity, $\sigma_{\mathrm{O}}$, can be expressed as

$$
\sigma_{\mathrm{O}}=\left[\beta \cdot x\left(\mathrm{O}_{\mathrm{i}}^{\prime \prime}\right)\right] \cdot 2 e \cdot u\left(\mathrm{O}_{\mathrm{i}}^{\prime \prime}\right) \cdot \frac{x\left(\mathrm{I}_{\mathrm{i}}^{\times}\right)}{6}
$$

where $x(\mathrm{D}), e$, and $u\left(\mathrm{O}_{\mathrm{i}}^{\prime \prime}\right)$ denote mole fraction of defect species (that is, $\beta \cdot x\left(\mathrm{O}_{\mathrm{i}}^{\prime \prime}\right)$ represents the concentration of mobile

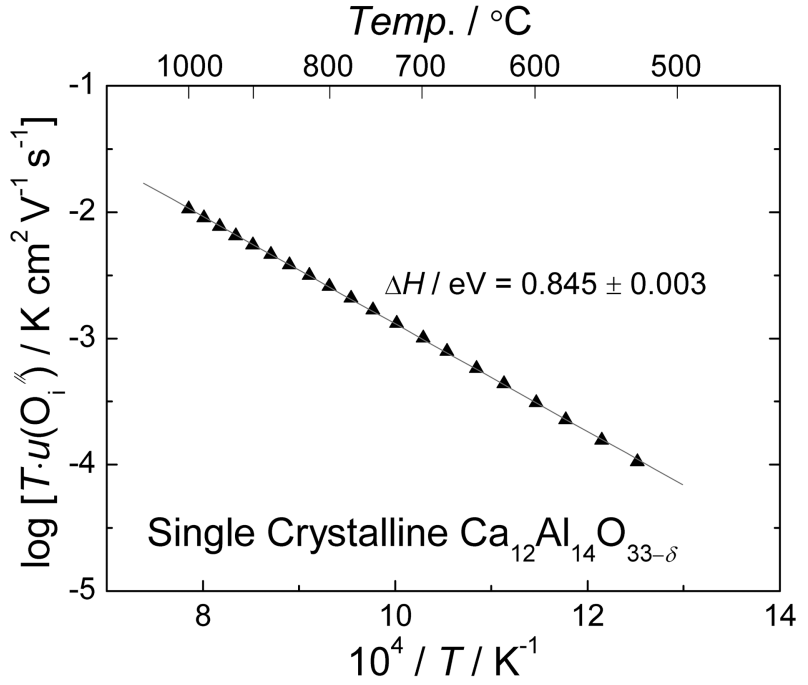

Fig. 5. Mobility of oxygen interstitial for single crystalline $\mathrm{Ca}_{12} \mathrm{Al}_{14} \mathrm{O}_{33-\delta}$

oxygen interstitial in $\mathrm{cm}^{-3}$ ), elementary charge, and electrochemical mobility of oxygen interstitial, respectively. It is noted that $x\left(\mathrm{I}_{\mathrm{i}}^{\times}\right) / 6$ reflects the probability of successful jumps of a displaced oxygen, $\mathrm{O}_{\mathrm{O}}^{\times}$, into a vacant interstitial site, $\mathrm{I}_{\mathrm{i}}^{\times}$. It is readily recognized that both $x\left(\mathrm{O}_{\mathrm{i}}^{\prime \prime}\right)$ and $x\left(\mathrm{I}_{\mathrm{i}}^{\times}\right)$ are constant as 1 and 5, respectively, due to Eq. (6) and site conservation constraint, $x\left(\mathrm{O}_{i}^{\prime \prime}\right)+x\left(\mathrm{I}_{\mathrm{i}}^{\times}\right)=6$, in the near stoichiometry regime. The observed total conductivity that remains unchanged in the oxygen activity range of $-15<$ $\log a_{\mathrm{O}_{2}} \leq 0$ in Fig. 2(b) is compatible with the present model that accounts for the ionic charge carrier concentration independent of oxygen activity. It is emphasized here that the high ionic conductivity in $\mathrm{Ca}_{12} \mathrm{Al}_{14} \mathrm{O}_{33}$ is a consequence of intrinsic crystal structure without additional doping.

The mobility of the oxygen interstitial as a function of reciprocal temperature from Eq. (8) as determined by Lee and Janek ${ }^{20)}$ is shown in Fig. 5. The calculated mobility, which is represented by linear regression as

$u\left(O_{i}^{\prime \prime}\right) / \mathrm{cm}^{2} \mathrm{~V}^{-1} \mathrm{~s}^{-1}=\frac{2.36 \times 10^{1.00 \pm 0.02}}{T}$

$\cdot \exp \left[-\frac{(0.845 \pm 0.003) \mathrm{eV}}{k T}\right]$

takes a value of $2.4 \times 10^{-6}<u\left(\mathrm{O}_{\mathrm{i}}^{\prime \prime}\right) / \mathrm{cm}^{2} \mathrm{~V}^{-1} \mathrm{~s}^{-1}<8.3 \times 10^{-6}$ in the temperature range of $1073 \leq \mathrm{T} / \mathrm{K} \leq 1273$.

As the oxygen activity decreases, on the other hand, the reduction of $\mathrm{C}_{12} \mathrm{~A}_{7}$ may proceed in such a way that the cage oxygen, $\mathrm{O}_{i}^{\prime \prime}$, is replaced by electron as described by Eq. (2). The reduction equilibrium can be schematically illustrated in an electron energy diagram as shown in Fig. 6, where solid and dotted bars represent the occupied electronic states of the oxygen interstitial (cage oxygen; free oxygen) and the vacant interstitial site (cage) that are spatially isolated, and the arrow the electron with two spin states. The electron mobility of $\mathrm{C}_{12} \mathrm{~A}_{7}$ were reported as $u_{\mathrm{n}} / \mathrm{cm}^{2} \mathrm{~V}^{-1} \mathrm{~s}^{-1}=$ 


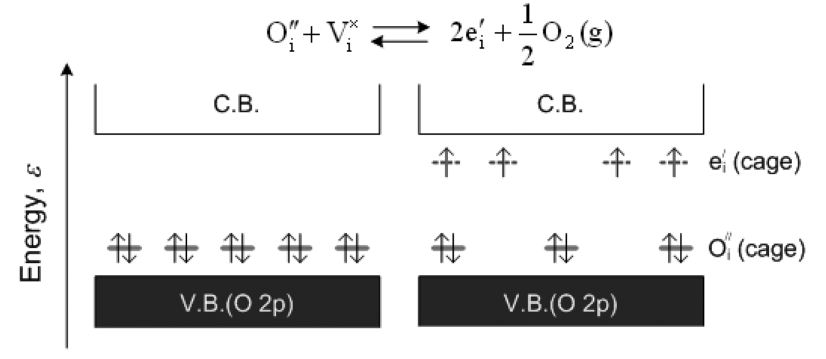

Fig. 6. Schematic of the change in electronic structure of $\mathrm{Ca}_{12} \mathrm{Al}_{14} \mathrm{O}_{33-\delta}$ by reduction. The occupied electronic states of oxygen interstitials and vacant interstitial sites are denoted by solid and dotted bars, and electrons by arrows.

0.34 (calculated from Ref. 25) or 0.1 for hopping electrons ${ }^{31)}$ and $u_{\mathrm{n}} / \mathrm{cm}^{2} \mathrm{~V}^{-1} \mathrm{~s}^{-1}=4$ for the electron in conduction band, ${ }^{31)}$ respectively, at room temperature. By comparing the reported values for the mobility of electron with that for the oxygen interstitial evaluated above, it can be deduced that the observed conductivity variation in the reducing condition, $\sigma \propto a_{O_{2}}^{-1 / 4}$ in Fig. 2(b), also belongs to the regime of $\left[\mathrm{D}_{\mathrm{FW}}^{\bullet \bullet}\right] \approx\left[\mathrm{O}_{\mathrm{i}}^{\prime \prime}\right]$ in the defect diagram (Fig. 4) with predominant ionic defect concentrations but with overwhelming electronic carrier mobilities.

The present defect model further anticipates that in the far reducing atmosphere the electron concentration will be saturated to a value of $2 \beta=2.32 \times 10^{21} \mathrm{~cm}^{-3}$ due to the electronic compensation, i.e., $n \approx 2\left[\mathrm{D}_{\mathrm{FW}}^{\bullet \bullet}\right]$. By reduction with $\mathrm{Ca}$ or Ti metals, ${ }^{9,31)}$ Hosono et al. have achieved extremely low oxygen activities corresponding to the equilibrium between metal and metal oxide and came close to this limit. Matsuishi et al. reported that $\mathrm{C}_{12} \mathrm{~A}_{7}$ reduced by $\mathrm{Ca}$ at $700^{\circ} \mathrm{C}$ for $240 \mathrm{~h}$, thereby showing temperature-independent conductivity, contained $2 \times 10^{21} \mathrm{~cm}^{-3}$ of electrons, and claimed that this value agreed well with the theoretical maximum of 2.33 $\times 10^{21} \mathrm{~cm}^{-3}$. ${ }^{9}$ However, the electron concentration in the crystal reduced by $\mathrm{Ti}$ at $900^{\circ} \mathrm{C}$ for $24 \mathrm{~h}$, of which conductivity is quite similar to the former in magnitude as well as in temperature dependence, was found to be $0.97 \times 10^{21} \mathrm{~cm}^{-3}{ }^{31)}$ Due to such an uncertainty it seems not really clear whether there is an achievable limit of the electron concentration in mayenite. We note that the validity of the pseudodonor model can be more unambiguously demonstrated by identifying the saturation in the electron concentration with decreasing $a_{\mathrm{O}_{2}}$, and that even higher electronic conductivity may be achieved if $\mathrm{C}_{12} \mathrm{~A}_{7}$ is made to reach the defect regime of $\left(\mathrm{V}_{\mathrm{O}}^{\bullet \bullet}, \mathrm{e}^{\prime}\right)$.

\subsection{Ionic transference number}

Summing up Eqs. (6) and (7), the conductivity isotherm as the sum of n-type conductivity $\sigma_{n}$ and constant ionic conductivity $\sigma_{\mathrm{o}}$ in the experimental condition of the present study, can be represented as

$$
\sigma=\sigma_{n}^{\circ} \cdot a_{\mathrm{O}_{2}}^{-1 / 4}+\sigma_{\mathrm{O}}
$$

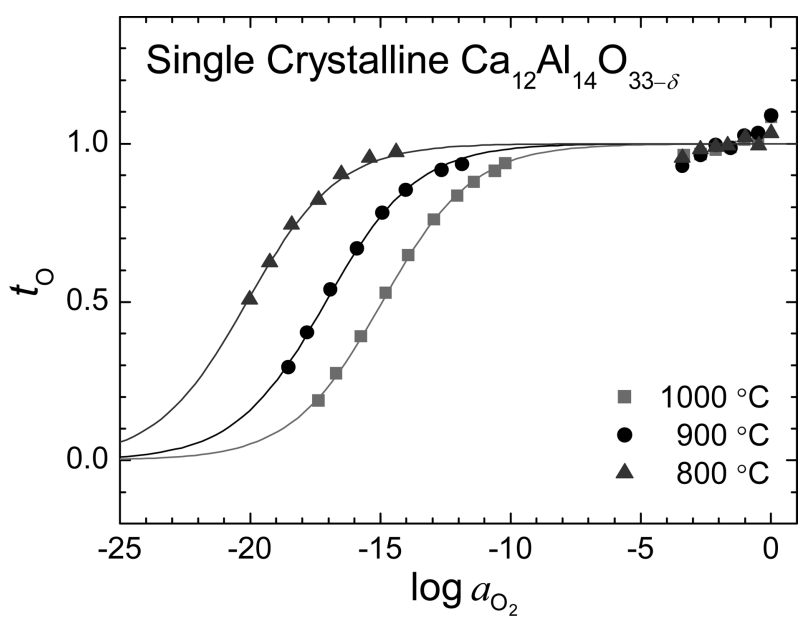

Fig. 7. Ionic transference number $t_{\mathrm{O}}$ vs. $\log a_{\mathrm{O}_{2}}$ for single crystalline $\mathrm{Ca}_{12} \mathrm{Al}_{14} \mathrm{O}_{33-\delta}$ (specimen \#1) at different temperatures. The solid lines are the calculated via Eq. (11).

based on the assumption that the mobilities of electronic and ionic carriers are independent of oxygen activity. Here, $\sigma_{\mathrm{n}}^{\circ}$ denotes the electronic partial conductivity at $a_{\mathrm{O}_{2}}=1$. The measured total conductivity was fitted by Eq. (10) as depicted by solid and dashed curves in Fig. 2(b), see Lee and Janek $^{20)}$ for details.

The ionic transference number $t_{\mathrm{O}}\left(\equiv \sigma_{\mathrm{O}} / \sigma\right)$ by using the numerical values for $\sigma_{\mathrm{O}}$ and $\sigma_{\mathrm{n}}^{\circ}$ results as

$$
t_{\mathrm{O}}=\frac{\sigma_{\mathrm{O}}}{\sigma_{\mathrm{O}}+\sigma_{\mathrm{n}}^{\circ} a_{\mathrm{O}_{2}}^{-1 / 4}}
$$

Fig. 7 shows $t_{\mathrm{O}}$ as a function of oxygen activity where the solid curves are calculated via Eq. (11). The ionic transference number $t_{0}$ of $\mathrm{C}_{12} \mathrm{~A}_{7}$ remains almost unity in the oxygen activity range of $\log a_{\mathrm{O}_{2}}>-8$ (ion conducting), and then decreases with decreasing $a_{\mathrm{O}_{2}}$ finally to the value close to 0 at around $\log a_{\mathrm{O}_{2}}=-20$ (electron conducting). The isothermal variation of $t_{0}$ from 1 to 0 , bridging two remarkable properties of $\mathrm{C}_{12} \mathrm{~A}_{7}$ as an electrolyte and an electride, clearly demonstrates the chemical route for its transition.

\subsection{Hydration mechanism}

Very early Lacerda reported that polycrystalline C12A7 is hygroscopic and that the ionic conductivity of $\mathrm{C} 12 \mathrm{~A} 7$ degrades by hydration. ${ }^{5)}$ Details on the hydration of mayenite have yet only been reported by Lee and Janek ${ }^{20)}$ and by Strandbakke et al.. ${ }^{32)}$ Lee and Janek studied the temporal evolution of the ionic conductivity upon hydration and found contradictory results, suggesting that the detailed mechanism of hydration in mayenite is far from simple: They found i) a short-term increase of conductivity (by about $40 \%$,) upon hydration using a water-saturated gas mixture $\left(p_{\mathrm{H}_{2} \mathrm{O}} /\right.$ $\left.10^{5} \mathrm{~Pa}=2.1 \times 10^{-2}\right)$ in a fixed oxygen partial pressure; ii) a long-term degradation at $900^{\circ} \mathrm{C}$ in a laboratory humidity.

Irvine and West $^{5)}$ suggested that water uptake leads to the formation of immobile hydroxides and hence reduces the 
(a)

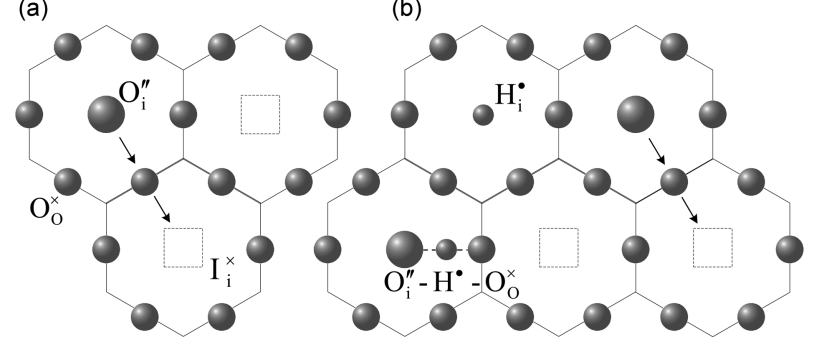

Fig. 8. Schematic illustration of the oxygen transport in $\mathrm{Ca}_{12} \mathrm{Al}_{14} \mathrm{O}_{33-\delta}$; (a) in dry condition, and (b) during hydration. Note that metal ions are not shown.

ionic conductivity. The proposed hydration reaction may be rewritten in terms of Kroeger-Vink notation as

$$
\mathrm{H}_{2} \mathrm{O}(\mathrm{g})+\mathrm{O}_{\mathrm{i}}^{\prime \prime}+\mathrm{I}_{\mathrm{i}}^{\times}=2 \mathrm{OH}_{\mathrm{i}}^{\prime} ; K_{\mathrm{H}}=\frac{\left[\mathrm{OH}_{\mathrm{i}}^{\prime}\right]^{2}}{\left[\mathrm{O}_{\mathrm{i}}^{\prime \prime}\right]\left[\mathrm{I}_{\mathrm{i}}^{\times}\right] a_{\mathrm{H}_{2} \mathrm{O}}}
$$

It has been reported that the $\mathrm{C}_{12} \mathrm{~A}_{7}$ uptakes up to $1.12 \mathrm{wt} \%$ $\mathrm{H}_{2} \mathrm{O}$ after annealing in air of normal humidity at $960^{\circ} \mathrm{C}$, resulting in the composition close to $\mathrm{C}_{12} \mathrm{~A}_{7}:\left(\mathrm{OH}^{-}\right)_{2}$, i.e., $\left[\mathrm{Ca}_{12} \mathrm{Al}_{14} \mathrm{O}_{32}\right]\left(\mathrm{OH}^{-}\right)_{2}$ (note that the incorporation of $1.3 \mathrm{wt} \%$ of $\mathrm{H}_{2} \mathrm{O}$ leads to the exact stoichiometric composition). By combined analysis of IR spectroscopy with thermodynamics, Hayashi et al. ${ }^{33)}$ demonstrated that hydration proceeds with the surface reaction via Eq. (12) followed by the chemical diffusion of $\mathrm{O}^{2-}$ and $\mathrm{OH}^{-}$ions, and the rate determining process of the latter is the inward bulk diffusion of $\mathrm{OH}^{-}$. According to their kinetic analysis, the chemical diffusion coefficient of the $\mathrm{H}_{2} \mathrm{O}$ molecule is smaller by 2 to 3 orders of magnitude than the self diffusion coefficient of oxygen ion, taking the value of $\tilde{D}_{\mathrm{H}_{2} \mathrm{O}} / \mathrm{cm}^{2} \mathrm{~s}^{-1}=5.15 \times 10^{-10}$ at $900^{\circ} \mathrm{C}$. This leads for samples with dimensions in the $\mathrm{mm}$ range to conductivity changes in the time range of some months.

The enhanced conductivity by $40 \%$ upon an abrupt change of atmosphere to a water-saturated one, as described by Lee and Janek, cannot be explained by Eq. (12) only. They rather suggest that the increased concentration of $\mathrm{OH}_{\mathrm{i}}^{\prime}$, which is determined by the equilibrium of the reaction Eq. (12), $\left[\mathrm{OH}_{\mathrm{i}}^{\prime}\right] \propto \alpha_{\mathrm{H}_{2} \mathrm{O}}^{1 / 2}$, may shift the equilibrium of the following reaction to the left.

$$
2 \mathrm{H}_{\mathrm{i}}^{\bullet}+2 \mathrm{O}_{\mathrm{i}}^{\prime \prime}=2 \mathrm{OH}_{\mathrm{i}}^{\prime}+2 \mathrm{I}_{\mathrm{i}}^{\times}
$$

which, in combination with Eq. (12), leads to

$$
\mathrm{H}_{2} \mathrm{O}(\mathrm{g})+\mathrm{O}_{\mathrm{i}}^{\prime \prime}+3 \mathrm{I}_{i}^{\times}=2 \mathrm{H}_{\mathrm{i}}^{\bullet}+2 \mathrm{O}_{\mathrm{i}}^{\prime \prime}
$$

Eq. (14) suggests that an incorporation of water into $\mathrm{C}_{12} \mathrm{~A}_{7}$ induces the increase in the concentration of the mobile oxygen interstitial $\mathrm{O}_{i}^{\prime \prime}$ as well as proton $\mathrm{H}_{i}^{\bullet}$ at the very initial stage of hydration. The transference number of the latter, however, was found to be negligibly small. ${ }^{34)}$ Thus, about $40 \%$ of enhancement in electrical conductivity may be attributed to the increase of $\left[\mathrm{O}_{\mathrm{i}}^{\prime \prime}\right]$ near the surface region only in the transient state of hydration.

This scenario may be schematically represented as shown in Fig. 8(b). The interstitialcy mechanism in dry condition is also illustrated in Fig. 8(a) for comparison. The metal ions are not shown for simplicity's sake.

\section{Summary and Conclusion}

The electrical transport properties and their dependence on the oxygen content (i.e. the degree of reduction) of $\mathrm{C}_{12} \mathrm{~A}_{7}$ can be well described within the framework of point defect thermodynamics. From the defect chemical point of view $\mathrm{C}_{12} \mathrm{~A}_{7}$ is an interesting example for a material with a structurally fixed number of mobile ionic charge carriers. Thus, it might be considered as a structurally disordered material, like e.g. the silver superionic conductors, but a different model appears to be more appropriate: Neglecting hydration effects, the ionic and electronic disorder can be described as follows: The framework $\left[\mathrm{Ca}_{12} \mathrm{Al}_{14} \mathrm{O}_{32}\right]^{2+}$ acts as a doubly charged pseudo-donor and is electrically compensated by a doubly ionized interstitial oxygen occupying one of six cages $\left(\mathrm{I}_{\mathrm{i}}^{\times}\right)$such that $\left[\mathrm{D}_{\mathrm{FW}}^{\bullet \bullet}\right] \approx\left[\mathrm{O}_{\mathrm{i}}^{\prime \prime}\right]$, which results in the electronic concentration varying as $n \propto a_{O_{2}}^{-1 / 4}, p \propto a_{O_{2}}^{+1 / 4}$. Thus, $\mathrm{C}_{2} \mathrm{~A}_{7}$ shows the same oxygen activity dependence of its partial conductivities as doped zirconia or ceria. The ionic transference number of $\mathrm{C}_{12} \mathrm{~A}_{7}$ decreases from 1 to 0 with decreasing oxygen activity, and its oxygen activity dependence can be well understood by this simple defect model. There is still the need for a quantitative study of the exact oxygen content -i.e. the nonstoichiometry is still an open question.

Hydration modifies the transport properties significantly - as is expected for a compound being composed of two highly basic oxides $\mathrm{CaO}$ and $\mathrm{Al}_{2} \mathrm{O}_{3}$. The decrease of conductivity by about two orders of magnitude as well as the increase of its activation energy by $1.79 \mathrm{eV}$ for the fully hydrated $\mathrm{C}_{12} \mathrm{~A}_{7}$ compared to dry one is attributed to the formation of immobile hydroxide. First quantitative results on the hydration behavior have been reported by Strandbakke et al.. ${ }^{32)}$ Also, recently Kim et al. $^{21)}$ have investigated the thermoelectric transport properties of mayenite which are fully in accord with the defect model presented here.

A different description of the defect chemistry of mayenite has been proposed by Strandbakke and Norby ${ }^{32)}$ in their paper on the hydration of mayenite. They use fractional defects in order to account for the structural disorder of mayenite. Their results on the total conductivity of hydrated mayenite is in full agreement with the results by Lee and Janek.

\section{Acknowledgments}

This study has been supported by the German Research Foundation within the priority program "Substitution Effect in Ionic Solids" (SPP 1136) under the project Ja 648/9. We thank M. Lerch and H. D. Wiemhöfer for a fruitful cooperation.

\section{REFERENCES}

1. K. L. Scrivener, "Historical and Present Day Applications of Calcium Aluminate Cements," pp. 3-23 in Calcium Alu- 
minate Cements 2001, ed. R. J. Mangabhai and F. P. Glasser, IOM communications Ltd., London, 2001.

2. M. Lacerda, J. T. S. Irvine, F. P. Glasser, and A. R. West, "High Oxide Ion Conductivity in $\mathrm{Ca}_{12} \mathrm{Al}_{14} \mathrm{O}_{33}$," Nature, 332 525-26 (1988).

3. J. Jeevaratnam, F. P. Glasser, and L. S. D. Glasser, "Anion Substitution and Structure of $12 \mathrm{CaO} \cdot 7 \mathrm{Al}_{2} \mathrm{O}_{3}$, J. $\mathrm{Am}$. Ceram. Soc., 47 105-6 (1964).

4. H. B. Bartl and T. Scheller, Neues Jahrb. Mineral., Monatsh., 35 547-52 (1970).

5. J. T. S. Irvine and A. R. West, J. Appl. Electrochem., 19 410-12 (1989).

6. M. Lacerda, A. R. West, and J. T. S. Irvine, "Electrical Properties of $\mathrm{Ca}_{12} \mathrm{Al}_{14} \mathrm{O}_{33}$ : Effect of Hydrogen Reduction," Solid State Ionics, 59 257-62 (1993).

7. P. V. Sushko, A. L. Shluger, K. Hayashi. M. Hirano, and H. Hosono, "Electron Localization and a Confined Electron Gas in Nanoporous Inorganic Electrides," Phys. Rev. Lett., 91126401 (2003).

8. K. Hayashi, S. Matsuishi, T. Kamiya, M. Hirano, and H. Hosono, "Light-Induced Conversion of an Insulating Refractory Oxide into a Persistent Electronic Conductor," Nature, 419 462-65 (2002).

9. S. Matsuishi, Y. Toda, M. Miyakawa, K. Hayashi, T. Kamiya, M. Hirano, I. Tanaka, and H. Hosono, "High-Density Electron Anions in a Nanoporous Single Crystal: $\left[\mathrm{Ca}_{24} \mathrm{Al}_{28} \mathrm{O}_{64}\right]^{4+}(4 \mathrm{e}-)$," Science, 301 626-29 (2003).

10. P. V. Sushko, A. L. Shluger, K. Hayashi, M. Hirano, and H. Hosono, "Role of Hydrogen Atoms in the Photoinduced Formation of Stable Electron Centers in $\mathrm{H}$-doped $12 \mathrm{CaO} \cdot 7 \mathrm{Al}_{2} \mathrm{O}_{3}$," Phys. Rev. B, 73045120 (2006).

11. P. V. Sushko, A. L. Shluger, M. Hirano, and H. Hosono, "From Insulator to Electride: A Theoretical Model of Nanoporous Oxide $12 \mathrm{CaO} \cdot 7 \mathrm{Al}_{2} \mathrm{O}_{3}$, J. Am. Chem. Soc., 129 942-51 (2007).

12. S. Matsuishi, S. W. Kim, T. Kamiya, M. Hirano, and H. Hosono, "Localized and Delocalized Electrons in RoomTemperature Stable Electride $\left[\mathrm{Ca}_{24} \mathrm{Al}_{28} \mathrm{O}_{64}\right]^{4+}(\mathrm{O} 2-)_{2-\mathrm{x}}(\mathrm{e}-)_{2 \mathrm{x}}$ : Analysis of Optical Reflectance Spectra," J. Phys. Chem. C, 112 4753-60 (2008)

13. J. E. Medvedeva, A. J. Freeman, M. I. Bertoni, and T. O. Mason, "Electronic Structure and Light-Induced Conductivity of a Transparent Refractory Oxide," Phys. Rev. Lett., 93016408 (2004).

14. J. E. Medvedeva and A. J. Freeman, "Hopping versus Bulk Conductivity in Transparent Oxides: $12 \mathrm{CaO} \cdot 7 \mathrm{Al}_{2} \mathrm{O}_{3}$, , Appl. Phys. Lett., 85 955-57 (2004).

15. Z. Li, J. Yang, J. G. Hou, and Q. Zhu, "Is Mayenite without Clathrated Oxygen an Inorganic Electride?," Angew, Chem. Int. Ed., 43 6479-82 (2004).

16. L. Palacios, A. Cabeza, S. Bruque, S. Garcia-Granda, and M. A. G. Aranda, "Structure and Electrons in Mayenite Electrides," Inorg. Chem., 47 2661-67 (2008).

17. H. Hosono and Y. Abe, "Occurrence of Superoxide Radical Ion in Crystalline Calcium Aluminate $12 \mathrm{CaO} \cdot 7 \mathrm{Al}_{2} \mathrm{O}_{3}$ Prepared via Solid-State Reactions," Inorg, Chem., 26 1192-95 (1987).

18. K. Hayashi, M. Hirano, S. Matsuishi and H. Hosono, "Microporous Crystal $12 \mathrm{CaO} \cdot 7 \mathrm{Al}_{2} \mathrm{O}_{3}$ Encaging Abundant O- Radicals," J. Am. Chem. Soc., 124 738-39 (2002).

19. J. A. Imlach, L. S. D. Glasser, and P. F. Glasser, "Excess
Oxygen and the Stability of $12 \mathrm{CaO} \cdot 7 \mathrm{~A}_{2} \mathrm{O}_{3}$," Cement Conc. Res., 1 57-61 (1971).

20. D.-K. Lee, L. Kogel, S. G. Ebbinghaus, I. Valov, H.-D. Wiemhoefer, M. Lerch, and J. Janek, "Defect Chemistry of the Cage Compound, $\mathrm{Ca}_{12} \mathrm{Al}_{14} \mathrm{O}_{33-8}$ - Understanding the Route from a Solid Electrolyte to a Semiconductor and Electride," Phys. Chem. Chem. Phys., 11, 3105-14 (2009).

21. S. W. Kim, R. Tarumi, H. Iwasaki, H. Ohta, M. Hirano, and H. Hosono, "Thermal Conductivity and Seebeck Coefficient of $12 \mathrm{CaO} \cdot 7 \mathrm{Al}_{2} \mathrm{O}_{3}$ Electride with a Cage Structure," Phys. Rev. B, 80075201 (2009).

22. J. T. S. Irvine, M. Lacerda, and A. R. West, "Oxide Ion Conductivity in $\mathrm{Ca}_{12} \mathrm{Al}_{14} \mathrm{O}_{33}$ ", Mat. Res. Bull., 23 1033-38 (1988).

23. J.-H. Park and R. N. Blumenthal, "Electronic Transport in 8 Mole Percent $\mathrm{Y}_{2} \mathrm{O}_{3}-\mathrm{ZrO}_{2}$," J. Electrochem. Soc., 1362867 76 (1989).

24. M. Mogensen, T. Lindegaard, U. R. Hansen, and G.. Mogensen, "Physical Properties of Mixed Conductor Solid Oxide Fuel Cell Anodes of Doped $\mathrm{CeO}_{2}$," J. Electrochem. Soc., 141 2122-28 (1994).

25. S.-W. Kim, K. Hayashi, M. Hirano, and H. Hosono, "Electron Carrier Generation in a Refractory Oxide $12 \mathrm{CaO}$. $7 \mathrm{Al}_{2} \mathrm{O}_{3}$ by Heating in Reducing Atmosphere: Conversion from an Insulator to a Persistent Conductor," J. Am. Ceram. Soc., 89 3294-98 (2006).

26. H. Boysen, M. Lerch, A. Stys, and A. Senyshyn, "Structure and Oxygen Mobility in Mayenite $\left(\mathrm{Ca}_{12} \mathrm{Al}_{14} \mathrm{O}_{33}\right)$ : A HighTemperature Neutron Powder Diffraction Study," Acta Cryst., B63 675-82 (2007).

27. K. Hayashi, S. Matsuishi, M. Hirano, and H. Hosono, "Formation of Oxygen Radicals in $12 \mathrm{CaO} \cdot 7 \mathrm{Al}_{2} \mathrm{O}_{3}$ : Instability of Extraframework Oxide Ions and Uptake of Oxygen Gas," $J$. Phys. Chem. B, 108 8920-25 (2004).

28. O. Trofymluk, Y. Toda, H. Hosono, and A. Navrotsky, "Energetics of Formation and Oxidation of Microporous Calcium Aluminates: A New Class of Electrides and Ionic Conductors," Chem. Mater., 17 5574-79 (2005).

29. P. V. Sushko, A. L. Shluger, K. Hayashi, M. Hirano, and H. Hosono, "Mechanisms of Oxygen Ion Diffusion in a Nanoporous Complex Oxide $12 \mathrm{CaO} \cdot 7 \mathrm{Al}_{2} \mathrm{O}_{3}$," Phys. Rev. B, 73014101 (2006).

30. K. Kajihara, S. Matsuishi, K. Hayashi, M. Hirano, and H. Hosono, "Vibrational Dynamics and Oxygen Diffusion in a Nanoporous Oxide Ion Conductor $12 \mathrm{CaO} \cdot 7 \mathrm{Al}_{2} \mathrm{O}_{3}$ Studied by ${ }^{18} \mathrm{O}$ Labeling and Micro-Raman Spectroscopy," J. Phys. Chem. C, 111 14855-61 (2007).

31. S. W. Kim, S. Matsuishi, T. Nomura, Y. Kubota, M. Tanaka, K. Hayashi, T. Kamiya, M. Hirano, and H. Hosono, "Metallic State in a Lime-Alumina Compound with Nanoporous Structure," Nano Lett., 7 1138-43 (2007).

32. R. Strandbakke, C. Kongshaug, R. Haugsrud, and T. Norby, "High-Temperature Hydration and Conductivity of Mayenite, $\mathrm{Ca}_{12} \mathrm{Al}_{14} \mathrm{O}_{33}$, J. Phys. Chem. C, 113 8938-44 (2009).

33. K. Hayashi, M. Hirano, and H. Hosono, "Thermodynamics and Kinetics of Hydroxide Ion Formation in $12 \mathrm{CaO}$ $\cdot 7 \mathrm{Al}_{2} \mathrm{O}_{3}$," J. Phys. Chem. B, 109 11900-906 (2005).

34. K. Hayashi, P. V. Sushko, A. L. Shluger, M. Hirano, and H. Hosono, "Hydride Ion as a Two-Electron Donor in a Nanoporous Crystalline Semiconductor $12 \mathrm{CaO} \cdot 7 \mathrm{Al}_{2} \mathrm{O}_{3}$," J. Phys. Chem. B, 109 23836-42 (2005). 